\title{
MODO(S) DE VIDA E MODOS DE PRODUÇÃO DA EXISTÊNCIA HUMANA: ENSAIO TEÓRICO-METODOLÓGICO
}

\author{
MODO(S) DE VIDA Y MODOS DE PRODUCCIÓN DE LA EXISTENCIA HUMANA: \\ ENSAYO TEÓRICO-METODOLÓGICO
}

\section{WAY(S) OF LIFE AND WAYS OF PRODUCTION OF HUMAN EXISTENCE: THEORETICAL-METHODOLOGICAL ESSAY}

DOI: http://doi.org/10.9771/gmed.v13i2.43526

\author{
Lia Tiriba ${ }^{1}$
}

Resumo: Por ser um termo utilizado de forma imprecisa, o objetivo deste ensaio é apresentar um conceito de modo de vida substanciado na concepção materialista da história e da cultura, articulado à categoria modo de produção e a outros conceitos de junção. Referenciado em E. P. Thompson, busca-se o diálogo entre conceito e evidência interrogada, com perguntas de pesquisa que contribuem na análise de práticas econômico-culturais de grupos sociais, cujos modos de fazer, sentir e estar no mundo se constituem entre reprodução ampliada da vida e reprodução ampliada do capital. De cunho teórico-metodológico, o texto indica elementos materiais e simbólicos de modos de vida na atualidade histórica das comunidades tradicionais.

Palavras-chave: Modo de vida. Modo de produção. Cultura. História. Comunidades tradicionais.

Resumen: Por ser un término utilizado de manera imprecisa, el propósito de este ensayo es presentar un concepto de modo de vida sostenido en la concepción materialista de la historia y la cultura, vinculado a la categoría modo de producción y otros conceptos de entronque. Referido a E. P. Thompson, busca el diálogo entre concepto y evidencia interrogada, con preguntas de investigación que aporten al análisis de las prácticas económicas y culturales de grupos sociales, cuyas formas de hacer, sentir y estar en el mundo se componen entre la reproducción ampliada de la vida y la reproducción ampliada del capital. De carácter teórico y metodológico, el texto señala elementos materiales y simbólicos de modos de vida en el presente histórico de las comunidades tradicionales.

Palabras clave: Modo de vida. Modo de producción. Cultura. Historia. Comunidades tradicionales.

Abstract: As this is a term used imprecisely, the purpose of this essay is to present a concept of way of life substantiated in the materialist concept of history and culture, linked to the mode of production category and other junction-concepts. Referenced in E. P. Thompson, the dialogue between concept and interrogated evidence is sought, by means of researching questions that contribute to the analysis of economic and cultural practices of social groups, whose ways of doing, feeling and being in the world constitute between amplified reproduction of life and amplified reproduction of capital. Theoretical and methodological in nature, this essay indicates material and symbolic elements of ways of life in the historical present of traditional communities.

Keywords: Way of life. Production mode. Culture. History. Traditional communities.

\section{Introdução}


"As palavras não foram feitas para brilhar; as palavras foram feitas para dizer", assim dizia Graciliano Ramos (2015), depois de descrever o processo de trabalho d'As Lavadeiras de Alagoas. Aproximam-se do rio, mergulham as roupas sujas na água, torcem, sacodem, molham mais uma vez... Depois de tê-las estirado, deitam as roupas em cima das pedras, ensaboam de um lado, viram e ensaboam do outro. Esfregam. Sem torcer, enrolam cada uma das roupas para, com força, batê-las nas pedras. Retiram as roupas das pedras, enxaguam e voltam a enxaguar até que tenham certeza de que o sabão saiu completamente. À parte, em bacias bem ariadas, dissolvem o anil na água e mergulham as roupas, que ali permanecem para quarar, até que os olhos comprovem que estão limpas e claras como a água. Voltam ao rio, mergulham as roupas na água várias vezes, estendem no varal e esperam até secar.

Dialogando com Graciliano Ramos, é importante registrar que, em algumas regiões do Brasil, o modefazê das lavadeiras pode vir acompanhado de cantorias que ajudam passar o tempo, amenizar a dureza do trabalho, embalar os sonhos e, ao mesmo tempo, lavar a alma e celebrar a vida (como manda a tradição no Vale do Jequitinhonha, em Minas Gerais, por exemplo)². Como dizia Marx, ao analisar a cooperação no trabalho como uma prática social que acompanha a história da humanidade, "o simples contato social provoca emulação entre os participantes, animando-os e estimulando-os [...]", criando uma "[...] força produtiva nova, a saber, a força coletiva" de trabalho (MARX, 1980, p. 375). Trabalho e cultura se constituem dialeticamente. Nesse sentido, podemos dizer que a cultura do trabalho se refere às maneiras de pensar, de sentir e de se relacionar com o trabalho. Diz respeito aos elementos materiais (instrumentos, métodos, técnicas, etc.) e simbólicos (atitudes, ideias, crenças, hábitos, representações, costumes) que constituem o processo de trabalho e que são partilhados pelos grupos humanos - considerados em suas especificidades de classe, gênero, etnia, religiosidade e geração. Relaciona-se ao papel dos sistemas simbólicos na vida social e, em especial, dos valores morais atribuídos à atividade de trabalho. Em última instância, remete-nos a objetivos e a formas de dispêndio da força de trabalho, o que requer a compreensão das relações sociais de produção que os grupos e as classes sociais, historicamente, estabelecem entre si (TIRIBA; SICH, 2012). Nessa perspectiva, as práticas econômicas e culturais vão se tecendo dialeticamente no mundo, na mesma "rede de relações", como nos adverte o historiador E. P. Thompson (2001, p. 208).

Parafraseando Marx (1980, p. 146), assim como "o sabor do pão não revela quem plantou o trigo", tampouco a brancura da roupa revela em que relações sociais de produção se dá o processo de trabalho da lavadeira: se sob o "chicote do feitor de escravos ou o olhar ansioso do capitalista". Uma questão a considerar é que, ao longo do capitalismo, entendido como processo histórico estruturado (THOMPSON, 1981), as águas límpidas dos rios foram sendo poluídas e suas fontes se tornaram ameaçadas por processos de industrialização e urbanização crescentes. Embora não seja nosso propósito aprofundar questões relativas à produção destrutiva do capital (MÉSZÁROS, 2002), o fato é que pode haver uma seca e faltar água! Com as mudanças climáticas, o rio pode transbordar... Uma hidrelétrica pode mudar o curso do rio e expulsar a comunidade para lugares onde o lençol freático pode estar contaminado 
pelo uso intensivo de agrotóxicos e fertilizantes. Sem falar que máquinas de lavar roupa, secadoras e outras inovações tecnológicas produzem efeitos que podem tornar supérflua a força de trabalho das lavadeiras de Alagoas, do Vale do Jequitinhonha, ou de qualquer região, provocando mudanças profundas nos "modos de vida" das lavadeiras (se é esse o conceito que poderíamos mobilizar para analisar as transformações no mundo do trabalho e, por conseguinte, as mudanças na vida dos trabalhadores e das trabalhadoras, ainda que não se reconheçam ou se identifiquem como classe trabalhadora).

Embora possamos utilizá-las de forma poética, "as palavras não foram feitas para brilhar; foram feitas para dizer". As palavras nomeiam as coisas materiais e simbólicas, expressam ações, pensamentos, estruturas e sentimentos. Expressam, como diria Thompson (1998), as necessidades e as expectativas de homens e mulheres sobre as relações entre seres humanos e natureza e de seres humanos entre si, relações essas mediadas pelo trabalho de produção da vida social. O mesmo acontece com outras palavras, quando elencamos possíveis categorias que podem nos aproximar das mediações, das contradições e das particularidades que constituem nossos objetos de pesquisa, buscando percebê-los em sua materialidade histórica, como totalidade social ${ }^{3}$.

À guisa de um ensaio, este texto decorre de estudos realizados no campo de pesquisa Trabalho e Educação. De nossa parte ${ }^{4}$, considerando os nexos trabalho e educação e economia e cultura como unidades dialéticas, temos insistido sobre a necessidade de contemplar culturas do trabalho que, embora submersas e sob a hegemonia do modo de produção capitalista, podem ser entendidas como "espaços/tempos do trabalho de produzir a vida associativamente" (TIRIBA; FISCHER, 2013)5. De cunho teórico-metodológico, nosso objetivo é problematizar a categoria modo de vida, partindo do pressuposto de que, na perspectiva do materialismo histórico dialético, a mesma pode ganhar novos sentidos se entendida como expressão de uma cultura opositora (WILLIAMS, 2011), ou seja, como manifestação de um modo de produção da existência humana que, contraditoriamente, ora se confronta, ora se coaduna, ora volta a se confrontar com o modo de produção capitalista, o qual, historicamente, tem hegemonia sobre outros modos de produção. Como "toda vida social é essencialmente prática" (MARX; ENGELS, 1987, p. 14) e como conceito e evidência interrogada (THOMPSON, 1981) caminham de mãos dadas, não poderíamos deixar de apresentar os sujeitos coletivos que inspiram nossa reflexão: as formas como homens e mulheres, no atual contexto do capitalismo, produzem sua existência em comunidades tradicionais, conformando modos de vida que se distinguem da perspectiva de reprodução ampliada do capital.

\section{Modo(s) de vida e sua polissemia}

No Novo Dicionário da Lingua Portuguesa (FERREIRA, 1999, p. 935), o termo "modo de vida" pode ser apreendido como derivado da palavra "modo": "[Do lat. Modu], S.m. 1. Maneira, feição ou forma 
particular; jeito: modo de falar. 2. Sistema, prática, método: modo de vida, de trabalho". Diversas podem ser suas conotações!

Como se seu significado fosse óbvio e resultasse de um consenso entre autores de diferentes matrizes teórico-metodológicas, observamos que a expressão modo de vida se tornou comum no linguajar popular, sendo utilizada de forma vaga e imprecisa nas ciências humanas e sociais, em geral para fazer referência a mudanças culturais decorrentes de processos de urbanização e industrialização que incidem na vida cotidiana. Por ser um termo utilizado com diversas conotações, queremos reunir elementos que contribuam para um conceito de modo de vida substanciado na concepção materialista da história e da cultura, o que requer sua articulação com outras categorias que nos permitam entendê-lo como totalidade social, ou como dizia Marx (1978, p. 116), como "síntese de múltiplas determinações, isto é, unidade do diverso".

O termo modo de vida pode ser confundido ou apresentado como sinônimo de estilo de vida, conceito este que, para Pierre Bourdieu (1983), relaciona-se a habitus, ou seja, às formas de pensar, sentir e agir, as quais, sedimentadas no corpo, manifestam a interiorização da estrutura social na conformação da estrutura mental. Fundamentado no livro La distinción, Julian Duval (2017) lembra que, para Bourdieu, estilo de vida diz respeito a práticas dos grupos sociais e das frações de classe em relação ao gosto musical, a preferências de esporte e lazer e a outras formas de consumo de bens materiais e simbólicos, dependendo das condições econômicas e sociais dos sujeitos.

Em tempos de neoliberalismo e protofascismo, não menos importante seria apreender o conceito de tribos urbanas, anunciado pelo sociólogo francês Michel Maffesoli (1987) no livro O tempo das tribos: declínio do individualismo na sociedade de massas, referido a grupos sociais urbanos não formais que buscam contestar uma determinada ordem e fazer frente ao poder socialmente instituído. Mas, se considerarmos o termo tribo como expressão de modo de vida ou associado à noção de estilo de vida, nos caberia observar a maneira de viver e sentir de pequenos grupos de amigos, de vizinhança ou de comunidade, tanto no campo como na cidade, que se identificam pelo sonho ou pela possibilidade real de escolher modos de produzir a existência humana que se contrapõem à sociabilidade do capital.

A expressão modo de vida também pode se aproximar, entre outros, do conceito de meios de vida, utilizado por Antônio Candido (2010) em Os parceiros do Rio Bonito, indicando a necessidade de elencar as condições objetivas-subjetivas da existência humana, o que requer como fundamento empírico a apreensão de suas raízes históricas. Nessa perspectiva, analisa a vida familiar, as formas de subsistência, as representações mentais, as relações de trabalho, a solidariedade e outras formas de sociabilidade que, ao longo do processo de expansão capitalista, vão conformando e transformando a vida do caipira paulista ${ }^{6}$.

Para problematizar noções ou conceitos de modo de vida orientados pela concepção materialista da história e da cultura, seria condição sine qua non mobilizar alguns conceitos de junção (THOMPSON, 1981). Destacamos o de vida cotidiana em Agnes Heller (1991), apresentado no livro Sociologia de la vida cotidiana, anunciado com possibilidade do cotidiano se tornar "vida sensata". Dado que o ser humano, em 
sua individualidade, não é uma substância fechada em si mesmo, mas um ser em desenvolvimento, cujo limite é a sua própria morte, "el hombre que lleva una vida sensata, plasma su próprio mundo en un paranosotros cambiándolo y transformándolo continuamente - y cambiándose y transformándose continuamente a sî mismo” (HELLER, 1991, p. 416). Para Gyorgy Lukács (1991), que pouco antes de sua morte, ocorrida em 1971, prefaciou Sociologia de la vida cotidiana, a obra de Heller pode ser considerada como síntese de uma antropologia crítica marxista. Sem desconsiderar as contribuições de Henri Lefebvre (1984) em La vida cotidiana en el mundo moderno, o autor considera que o escrito de Agnes Heller "representa uno de los estúdios más importantes de todo el campo de investigación sobre la génesis y el devenir del ser social concreto" (LUKÁCS, 1991, p. 14). Para ele, a vida cotidiana é a forma imediata como se manifesta o ser humano na sua generalidade. São as reações espontâneas dos seres humanos ao seu ambiente social, as quais podem aparecer de forma caótica, "pero precisamente por esto está contenida en ella la totalidade de los modos de reacción, naturalmente no como reacciones puras, sino más bien caótico-heterogéneas” (LUKÁCS, 1991, p. 12).

Em minucioso estudo sobre a utilização do termo nas literaturas francesa, inglesa e brasileira, em especial na sociologia e na antropologia, Braga, Fiuza e Remoaldo (2017) destacam que, nas origens da sociologia, o mesmo aparece para analisar a passagem das sociedades pré-capitalista para as sociedades industriais, com destaque ao mundo rural, no qual a vida em "comunidade" cede lugar para a vida em "sociedade". Para os autores, embora utilizado com diversas conotações, "o constructo 'modo de vida' serviu de forma clara para apontar as transformações das sociedades tradicionais em meio ao avanço da cultura urbana ao longo do século XX” (BRAGA; FIUZA; REMOALDO, 2017, p. 375). E ainda hoje, no século XXI, são imprecisos os significados a ele atribuídos, o que é dificultado pelas traduções para o português de genre de vie, style de vie, way of life, livelihood e de outros termos utilizados nas literaturas francesa e inglesa, fazendo com que o texto em língua portuguesa não corresponda, necessariamente, à ideia concebida na língua original. De qualquer maneira, segundo os autores "há uma certa convergência em seu entendimento ora como cultura, ora como cotidiano, ora como adaptação dos meios de produção à natureza" (BRAGA; FIUZA; REMOALDO, 2017, p. 389).

Importante destacar que, com o intuito de problematizar a categoria modo de vida, Gonçalves (apud BRAGA; FIUZA; REMOALDO, 2017, p. 375) indica o desdobramento do constructo modo de vida em dois aspectos: 1) condições de vida, ou seja, aos condicionantes da vida em sociedade e 2) ao estilo de vida, ou seja, "nas singularidades presentes nas pessoas e em pequenos grupos, abarcando os hábitos, normas e valores expressos pelos indivíduos”.

De nossa parte, entendemos ser fundamental elencar as múltiplas dimensões da vida material e simbólica que conformam os modos de vida dos grupos humanos, mas todo o cuidado é pouco para não cair em duas armadilhas: a primeira é a perspectiva culturalista de modo de vida, quer dizer, concepções fundadas na compreensão de cultura desvinculada das condições materiais de vida. Em outro extremo, a segunda armadilha é a possibilidade de cair no reducionismo econômico, estabelecendo uma rígida 
fronteira entre infraestrutura e superestrutura e, portanto, entre economia e cultura (como se a vida fosse organizada em polos dicotômicos).

\section{Economia, cultura, modos de vida e modos de luta}

Como Marx (1978), entendemos que, por ser abstrata, toda categoria só tem validade se entendida na sua historicidade, o que requer o entendimento de modo de vida como um conceito que, embora elástico (THOMPSON, 1981), tem como base material o modo de produção que é hegemônico a outros modos de produção da existência humana. Assim, nada melhor que voltar à Ideologia Alemã, em cuja obra Marx e Engels (1987, p. 27) afirmam que "produzindo seus meios de vida, os homens produzem, indiretamente, sua própria vida material". Os autores ressaltam que "tal modo de produção" não pode ser entendido "de um único ponto de vista, a saber: a reprodução da existência física dos indivíduos [...]”, pois, na verdade, trata-se de considerar "[...] uma determinada forma de manifestar a sua vida, determinado modo de vida dos mesmos". A forma como manifestam suas vidas coincide com o que eles são; coincide, portanto, com a forma como produzem a si mesmos, "tanto com o que produzem, como o modo como produzem. O que os indivíduos são, portanto, depende das condições materiais de sua produção" (MARX; ENGELS, 1987, p. 27-28). Assim, a noção de modo de vida aparece diretamente relacionada aos modos de produção da existência humana, os quais pressupõem formações sociais com regimes de propriedade dos meios de produção que modificam as relações sociais. E como Marx (1978, p. 114) assegura na Introdução à crítica da economia politica, trata-se de "saber de que maneira as condições históricas gerais afetam a produção e qual é a relação desta como o movimento histórico".

Refletir sobre a materialidade dos processos de produção da existência humana requer considerar que para viver e "fazer história", os seres humanos precisam "antes de tudo comer, beber, ter habitação, vestir-se [...]". (MARX; ENGELS, 1987, p. 39). Se "o ser dos homens é seu processo de vida real” (MARX; ENGELS, 1987, p. 37), podemos considerar que, ao produzir seus meios de vida, os seres humanos também produzem cultura e trabalham de acordo com uma determinada cultura. Embora não se refira à palavra cultura, Marx (1978, p. 110) analisa que, por ser determinada socialmente, "a produção de indivíduos não cria somente um objeto para o sujeito, mas também um sujeito para o objeto". Dessa maneira, "a fome é a fome, mas a fome que se satisfaz com garfo e faca é uma fome muito distinta da que devora carne crua com unhas e dentes". Em outras palavras, concebida como processo estruturado (THOMPSON, 1981), a história é mediada por condições objetivas/subjetivas que materializam determinados modos de estar, sentir, fazer e pensar o mundo.

Como totalidade, o modo de produção da vida tem como centralidade o trabalho, que pressupõe a experiência humana individual e coletiva, carregada de costumes, tradições, normas e valores. Nesse sentido, assim como a categoria cultura só pode ser entendida no lugar material que lhe corresponde (THOMPSON, 1998; WILLIAMS, 2011), o mesmo ocorre com modo de vida, que diz 
respeito às manifestações das relações que os seres humanos, mediados pelo trabalho, estabelecem com a natureza e entre si.

Embora a economia possa se constituir como determinação em última instância, o concreto é concreto por ser a síntese de múltiplas determinações (MARX, 1978), o que nos faz reafirmar que, nos modos de produção da existência, materializados em modos de vida, economia e cultura vão se enredando histórica e cotidianamente nas relações sociais que homens e mulheres estabelecem no processo social. Se, de acordo com a perspectiva da história dos de baixo, a classe é uma formação tanto econômica como cultural, é importante ter em conta que,

há um sem-número de contextos e situações em que homens e mulheres, ao se confrontar com as necessidades de sua existência, formulam seus próprios valores e criam sua cultura própria, intrínsecos ao seu modo de vida (THOMPSON, 2001, p. 200).

Desse autor, também apreendemos que toda luta de classes é luta por valores (THOMPSON, 1981), o que nos leva a inferir que a afirmação de que um modo de vida pressupõe a existência de modos de luta como forma de resistência ${ }^{7}$. Por isso, na trilha de Raymond Williams, pensamos que, embora o modo de produção capitalista tenha a hegemonia (que não é um conceito estático) sobre outros modos de produção da existência, é preciso considerar o que está "fora" do modo dominante, pois:

Nenhum modo de produção e, portanto, nenhuma sociedade dominante ou ordem da sociedade e, destarte, nenhuma cultura dominante pode esgotar toda gama de prática humana e da intenção humana (essa gama não é o inventário de alguma 'natureza humana’ original, mas ao contrário, é aquela gama extraordinária de variações práticas e imaginadas pelas quais seres humanos se veem como capazes) (WILLIAMS, 2011, p. 59).

O escopo deste texto não nos permite analisar as "variações práticas e imaginadas" que conformam os modos de vidas em comunidades tradicionais que temos pesquisado: quilombolas, ribeirinhos, castanheiros, seringueiros e pescadores pantaneiros ${ }^{8}$. Mas vale destacar que as práticas sociais desses e de outros grupos sociais, seus modos de fazer, sentir e estar no mundo, embora distintos do modo capitalista de produção da existência, circunscrevem-se entre a reprodução ampliada da vida e a reprodução ampliada do capital (TIRIBA, 2018).

Nossas pesquisas indicam que, tecidas por fios (in)visíveis de cor de pele, gênero, etnia e geração, as culturas do trabalho dos povos e comunidades tradicionais, materializadas em modos de vida, corroboram para a construção de sociabilidades fundadas na lógica da reprodução ampliada da vida. Permitem-nos afirmar que, ainda que de forma contraditória, essas comunidades carregam elementos de produção associada (TIRIBA; FISCHER, 2013). Afinal, "apenas na coletividade [de uns e outros] é que cada indivíduo encontra os meios de desenvolver suas capacidades em todos os sentidos; somente na coletividade, portanto, torna-se possível a liberdade pessoal” (MARX; ENGELS, 1987, p. 117).

Nossas incursões em Mato Grosso, Pará, Bahia e Rondônia indicam que o capitalismo cria condições objetivas/subjetivas para que as pessoas se submetam aos imperativos do capital. É nessa 
perspectiva que se verificam o cercamento físico e simbólico dos campos e a disputa e apropriação privada das terras comunais, provocando a degradação do outro (MARTINS, 2019). Logo, é preciso considerar que os modos de vida no campo têm sido fortemente marcados por políticas públicas econômicas, educativas e culturais e, agora mais que nunca, por políticas anti-ambientais e de devastação que se coadunam com os interesses do capital, hoje em sua forma mais conservadora e perversa. Como assinalou Rosa Luxemburgo (1970, p. 317), “o capitalismo aparece e se desenvolve historicamente num meio social não capitalista" e, para que possa se expandir, promove a desintegração e a dissolução contínua da economia natural e da economia rural. Nesse processo, o militarismo se constitui como estratégia e campo de acumulação do capital ${ }^{9}$. E não por acaso, historicamente, os povos e comunidades tradicionais têm resistido e lutado arduamente para assegurar modos de vida, que se substanciam na reprodução ampliada da vida, como nos ensina Souza (2020).

\section{Aproximações a um conceito elástico de modo de vida}

Para Thompson (1981, p. 185), "ao recusar a investigação empírica, a mente está para sempre confinada aos limites da mente". Por não poder caminhar "do lado de fora", a mente fica "imobilizada pela câimbra teórica". Assim, tendo em conta nossos estudos teóricos e empíricos desenvolvidos em comunidades tradicionais, nas quais homens e mulheres insistem em preservar e defender suas formas de estar no mundo, definimos como modo de vida um conjunto de práticas sociais, econômicas e culturais cotidianas compartilhadas por um determinado grupo social no processo de produção da vida material e simbólica. Como expressão da cultura, diz respeito aos costumes, às tradições, aos valores, às crenças e aos saberes que orientam as normas de convivência na vida familiar, no trabalho e em âmbito comunitário. Relaciona-se às maneiras de produzir, consumir e distribuir os frutos do trabalho, tendo em conta as formas de sentir e pensar a vida e o mundo. Os modos de vida manifestam as relações que homens e mulheres trabalhadoras mediadas pela memória coletiva e por experiências vividas e herdadas, estabelecem com o território em que produzem sua existência. A afirmação de modos de vida, entendidos como patrimônio cultural e, ao mesmo tempo, condição de existência humana, é, como Souza (2020) nos indica, elemento de resistência e negação de outros modos de produção da vida social, os quais, de alguma maneira, entrelaçam-se em menor ou maior grau, de acordo com as determinações dos contextos de luta por hegemonia.

A definição e a densidade de um conceito pressupõem a apreensão de algum tipo de norma ou regularidade dos fenômenos que permita certa generalização. Por isso, como adverte Thompson (1981, p. 50), "são falsas todas as teorias que não estejam em conformidade com as determinações da evidência", a qual deve ser entendida sempre como "evidência interrogada". Também cabe lembrar que, pela sua natureza, todo conhecimento é 
(a) provisório e incompleto (mas não por isso inverídico), (b) seletivo (mas não por isso inverídico), (c) limitado e definido pelas perguntas feitas à evidência (e os conceitos que informam essas perguntas), e, portanto, só 'verdadeiro' dentro do campo assim definido (THOMPSON, 1981, p. 49).

Sendo assim, para insistir na formulação de um conceito fundamentado na concepção materialista da história e da cultura, nossa hipótese é que a apreensão da objetividade material e simbólica do modo de vida de um grupo social tem como referência empírica questões de ordem econômicocultural que, em última instância, configuram-se como perguntas pertinentes à economia política. À guisa de uma Enquete Operária (MARX, 1982) e por meio de uma pesquisa de cunho participativo que envolva as pessoas da comunidade, seria interessante nos perguntar, entre outras questões:

Mediados pelo trabalho, que relações homens e mulheres estabelecem com a natureza? Qual o objetivo do trabalho? O que produzem e como produzem? Para que e para quem trabalham? ${ }^{10}$ Existe exploração do trabalho? Como são as relações de convivência no trabalho e em âmbito comunitário? Quais os critérios para distribuir os frutos do trabalho? Que sentidos são atribuídos ao trabalho de produção da vida? Quais são as tradições, os costumes, as crenças e os valores que orientam a vida comunitária? Como a religiosidade se manifesta? Que relações estabelecem com o tempo de trabalho e com o tempo de ócio? Que relações estabelecem com a natureza e com o território onde produzem sua existência? Tendo como referência as unidades domésticas, quais são os parâmetros de qualidade de vida? O que dizem as crianças, os jovens e os adultos sobre a vida em comunidade? O que desejam para si, seus familiares e demais moradores? ${ }^{11}$ Quais são os saberes do trabalho? O que a vida ensina? O que a escola ensina? Quais as mediações do capital na conformação das maneiras de fazer, sentir e pensar a vida em comunidade? E em relação ao Estado? Quais são os conflitos, as dificuldades, os desafios e as formas de luta para preservação da vida em comunidade?

Essas são algumas perguntas de pesquisa que podem permitir a apreensão do modo de vida das lavadeiras de Alagoas, ou do Vale do Jequitinhonha, cujos indícios estão na materialidade das culturas do trabalho em cada uma das regiões. Importante também é considerar as mediações do capital na conformação tanto da cultura do trabalho, quanto dos modos de vida dessas trabalhadoras. Entendemos que tanto no campo da sociologia, como da antropologia (SOUZA; TIRIBA, 2017) proceder à descrição analítica de um modo de vida requer, entre outras ações, elencar elementos materiais e simbólicos que, constituindo-se como síntese de muitas determinações, isso é, como unidade do diverso (MARX, 1978), revelam a forma de ser e viver desse ou daquele grupo social. Em outras palavras, revelam as maneiras de atuar e estar no mundo, de pensar e sentir as relações entre seres humanos e natureza, mediadas pelo trabalho de produzir a existência humana.

Para prosseguir em novos ensaios... 
Entendemos que a história não é uma sucessão linear de modos de produção da existência movidos por leis fundamentais que corroboram para assegurar a Grande Teoria ou o Imperialismo Teórico, como denuncia Thompson (1981) em Miséria da Teoria. Tampouco é possível reduzir as "formações econômico-sociais a uma simples escada que todas as sociedades humanas sobem, degrau por degrau" (HOBSBAWM, 1985, p. 59). Mais que relíquias de passado, os modos de vida dos povos e comunidades tradicionais, por exemplo, são manifestações da materialidade de modos de produção da existência humana que permanecem vivos na história, ainda que de forma subordinada.

Nosso desafio é apreender a "estrutura na particularidade histórica do conjunto das relações sociais" (THOMPSON, 2001, p. 248), identificando modos de vida que, embora resistam, podem se tornar invisíveis frente à hegemonia do modo de produção capitalista em relação a outros modos de produção da existência humana. Carlos, um seringueiro que vive em uma das seis comunidades tradicionais que se situam no interior da Reserva Extrativista do Rio Cautário (Rondônia), assegura que:

Os fazendeiros já teriam derrubado tudo isso aqui e plantado pasto. Porque se não tivesse os seringueiros, aí teria só os índios para proteger a mata, a floresta. E as pessoas, assim, de uma maneira geral, não querem respeitar os índios. Então nós somos uma força a mais, junto com os índios. Porque os fazendeiros sabem que se quiserem fazer isso aqui de pasto, vão ter que tirar nós daqui (TIRIBA; SOUZA, 2020, p. 311).

Sobre as lavadeiras de Alagoas e do Vale do Jequitinhonha (que inspiraram este ensaio), vale perguntar em que medida as mudanças no mundo do trabalho, sob a égide do capital, contribuíram para transformar as culturas do trabalho e seus modos de vida? Quanto ao modefazê e de viver das lavadeiras e de outras "ganhadeiras" da Lagoa do Abaeté (Bahia), sabemos que permanece vivo, na memória, o trabalho das mulheres escravizadas e libertas que, nos séculos XIX e XX, faziam "lavagem de ganho" e outros biscates para o sustento da família. Suas cantigas de roda, que continuam a ecoar nas vozes de mulheres e crianças, tornaram-se referência cultural.

No diálogo disciplinado entre conceito e evidência interrogada (THOMPSON, 1981), há muito que se pesquisar sobre modo de vida. Poderíamos dizer que os modos de vida são residuais? Alternativos? Opositores? Em relação a "culturas residuais" e a "culturas emergentes" é Raymond Williams quem nos ensina que esses modos de vida podem ser "alternativos" como podem, de fato, ser "opositores" ao modo de produção capitalista. Sobre a dificuldade de romper a hegemonia do capital sobre o trabalho, explica que "as dificuldades da prática humana fora ou em oposição ao modo dominante são obviamente reais", pois vão depender se as práticas se situam "em uma área em que a classe e a cultura dominantes têm um interesse e uma participação", podendo ser "se possível, incorporadas - ou então extirpadas com extraordinário vigor" (WILLIAMS, 2011, p. 59-60).

“As palavras não foram feitas para brilhar; as palavras foram feitas para dizer”, assim dizia Graciliano Ramos. Mas é preciso considerar que, ao longo da história, as palavras vão ganhando novos sentidos e, sendo assim, as categorias só têm validade se tomadas em sua materialidade histórica, como nos assegurou Marx (1978). Para não correr o risco de apreender a realidade na sua pseudoconcreticidade 
(KOSIK, 1976), ou de vir a enquadrá-la a partir de um tipo ideal weberiano, devemos ficar atentos para perceber o que nos diz Thompson (2001, p. 243) sobre a materialidade histórica da cultura: "todo significado é um significado dentro-de-um contexto e, enquanto as estruturas mudam, velhas formas podem expressar funções novas, e funções velhas podem achar sua expressão em novas formas". Nesse sentido, nada melhor que um conceito elástico de modo de vida.

\section{Referências:}

ALVES, Ana Elizabeth Santos; TIRIBA, Lia. Trabalho-Educação, Economia e Cultura em comunidades tradicionais: entre a reprodução ampliada da vida e a reprodução ampliada do capital. Trabalho necessário, v. 16, n. 31, p. 136 - 164, 2018.

BRAGA, Gustavo; FIÚZA, Ana Louise; REMOALDO, Paula. O conceito de modo de vida: entre traduções, definições e discussões. Sociologias, Porto Alegre, ano 19, n. 45, p. 370-396, mai-ago 2017.

BOURDIEU, Pierre. Sociologia. São Paulo: Ática, 1983.

CANDIDO, Antonio. Os parceiros do Rio Bonito: estudo sobre o caipira paulista e a transformação dos seus meios de vida. Rio de Janeiro: Ouro sobre azul, 2010.

DUVAL, Julien. Estilos de vida. In: CATANI, Afrânio M. et al (Orgs). Vocabulário Bourdieu. Belo Horizonte: Autêntica Editora, p. 187-189, 2017.

FERREIRA, Aurélio B. de Holanda. Novo dicionário da língua portuguesa. Rio de Janeiro: Editora Nova Fronteira, $1^{\text {a }}$ ed., 1999.

GARCIA, Jesús Jorge Pérez. Memorias de la revolución cubana: trabajo comunitário, educación y partipación popular. In: COLÓQUIO NACIONAL, 12.; COLÓQUIO INTERNACIONAL DO MUSEU PEDAGÓGICO, 5., 2017. Anais... Vitória da Conquista: Universidade Estadual do Sudoeste da Bahia, 2017.

HELLER, Agnes. Sociología de la vida cotidiana. Barcelona: Península, 1991.

HOBSBAWN, Eric. Introdução. In: MARX, Karl. Formações Econômicas Pré-Capitalistas. Rio de Janeiro: Editora Paz e Terra, 1985.

KOSIK, Karel. Dialética do concreto. Rio de Janeiro: Paz e Terra, 1976.

LEFVBRE, Henri. La vida cotidiana en el mundo moderno. Madrid: Alianza Editorial, 1984.

LUKÁCS, György. Prefacio. In: HELLER, Agnes. Sociología de la vida cotidiana. Barcelona: Península, 1991.

LUXEMBURGO, Rosa. A acumulação do capital. Rio de Janeiro: Zahar Editores, 1970.

MAFFESOLI, Michel. O Tempo das Tribos: o Declínio do Individualismo nas Sociedades de Massa. Rio de Janeiro: Forense Universitária, 1987.

MARTINS, José de Souza. Fronteira: a degradação do outro nos confins do humano. São Paulo: Contexto, 2019.

MARX, Karl. Para a crítica da economia política. In: . Manuscritos econômico-filosóficos e outros textos. São Paulo: Abril Cultural, 1978.

. O Capital: Crítica da economia política. Livro Primeiro: o processo de produção do capital. Tradução de Reginaldo Sant’ana. 5 ed. Rio de Janeiro: Civilização Brasileira, 1980. . O questionário de 1880. In: THIOLLENT, Michel. Crítica metodológica, investigação social e enquete operária. São Paulo: Polis, 1982, p. 249-256. 
MARX, Karl; ENGELS, Friedrich. A Ideologia Alemã. São Paulo: Hucitec, 1987.

MATTOS, Marcelo Badaró. E. P. Thompson e a tradição de crítica ativa do materialismo histórico. Rio de Janeiro: Editora da UFRJ, 2012.

MÉSZÁROS, István. Para além do capital. São Paulo: Boitempo Editorial, 2002.

NASCIMENTO, Claudio. A autogestão comunal. Marília: Lutas Anticapital, 2019.

RAMOS, Graciliano. Linhas Tortas. Rio de Janeiro: Editora Record, 2015.

SOUZA, William Kennedy do Amaral. Trabalho-educação, economia e cultura em povos e comunidades tradicionais: a (re)afirmação do modo de vida como formas de resistência. 2020. $222 \mathrm{f}$. Tese (Doutorado em Educação) - Programa de Pós-Graduação em Educação. Universidade Federal Fluminense, Niterói.

SOUZA, William; TIRIBA, Lia. Nexos entre economia e cultura: contribuições do materialismo histórico e da antropologia marxista. Trabalho Necessário, ano 15, n. 28, p. 24-43, 2017.

TIRIBA, Lia. Economia popular e cultura do trabalho: pedagogia(s) da produção associada. Ijuí: UNIJUÍ, 2001.

Reprodução ampliada da vida: o que ela não é, parece ser e pode vir a ser. Otra Economía, v.11, n. 20, p, 74-87, jul.-dic., 2018.

TIRIBA, Lia; SICHI, Bruna. Cios da terra: saberes da experiência e do trabalho associado. Trabalho Necessário, ano 10, n. 15, p. 1-30, 2012.

TIRIBA, Lia; FISCHER, Maria Clara Bueno. Aprender e ensinar a autogestão: espaços/tempos do trabalho de produzir a vida associativamente. Revista Perspectiva, Florianópolis, v. 31, n. 2, p. 527-551, 2013.

Espaços/tempos milenares dos povos e comunidades tradicionais: notas de pesquisa sobre economia, cultura e produção de saberes. Revista de Educação Pública, Cuiabá, v. 24, n. 56, p. 405-428, 2015 .

TIRIBA, Lia; SANTANA, Fernanda. Do diário de campo: conversas com pescadoras/es do pantanal mato-grossense sobre cultura do trabalho. Trabalho e Educação, Belo Horizonte, v.26, n. 2, p. 65-84, mai-ago, 2017.

TIRIBA, Lia; MAGALHÃES, Lívia Diana Rocha (Orgs). Experiência: o termo ausente? Uberlândia: Editora Navegando, 2018.

TIRIBA, Lia; SOUZA, William. Culturas do trabalho, educação e formas não capitalistas de produção da existência: entre quilombolas, castanheiros e seringueiros. Revista da ABET, v. 19, n. 2, p. 300-316, 2020. Acesso em: 19 fev. 2020. Disponível em: https://bit.ly/2NGtCoE

THOMPSON, Edward Palmer. A miséria da teoria ou um planetário de erros - uma crítica ao pensamento de Althusser. Rio de Janeiro: Zahar Editores, 1981.

das Letras, 1998.

Costumes em comum: estudos sobre a cultura popular tradicional. São Paulo: Companhia

. Folclore, antropologia e história social. In: NEGRO, Antônio Luigi; SILVA, Sérgio (Orgs). As peculiaridades dos ingleses e outros artigos. Campinas: Editora da Unicamp, 2001.

WILLIAMS, Raymond. Cultura e Materialismo. São Paulo: Editora Unesp, 2011.

WOOD, Ellen M. As origens agrárias do capitalismo. Crítica Marxista, São Paulo, Boitempo, v. 1, n. 10, p. 12-29, 2000. 


\begin{abstract}
Notas
${ }^{1}$ Doutora em Ciências Políticas e Sociologia pela Universidade Complutense de Madrid; professora no Programa de Pós- Graduação em Educação da Universidade Federal Fluminense; Núcleo Trabalho e educação (Neddate) - <http://neddate.sites.uff.br/>; Lattes: <http://lattes.cnpq.br/2006259738336754>; ORCID: <https://orcid.org/0000-0003-0117-4160>; Email: liatiriba@gmail.com

2 Entre outros, ver os documentários do cineasta Leon Hirszman, realizados entre 1974 e 1976, sobre os cantos entoados pelos trabalhadores rurais. São "cantos de trabalho" nas plantações de cana-de-açúcar, em Feira de Santana; de cacau, em Itabuna e nos mutirões (ajuda mútua), em Chã Preta. Neste endereço eletrônico se encontra um de seus documentários: https://www.youtube.com/watch?v=kNTZLi1mUJA

${ }^{3} \mathrm{Na}$ perspectiva do materialismo histórico, no caso da autora deste ensaio, destacam-se: economia popular, economia popular solidária, cultura do trabalho, produção associada, autogestão do trabalho e da vida social, reprodução ampliada da vida e, atualmente, modo de vida.

${ }^{4}$ Como, por exemplo, o intitulado Trabalho-educação, modos de vida e modos de produção da existência humana: a construção do "comum" em comunidades tradicionais, que conta com a participação de Maria Clara Victorino Barreto Lima, graduanda em Serviço Social (UFF) e bolsista de Iniciação Científica (PIBIC/UFF).

5 Podem ser considerados, pelo menos, três os "espaços/tempos do trabalho de produzir a vida associativamente". A) Espaços/tempos revolucionários - quando são produzidas mudanças estruturais na sociedade, verifica-se a dualidade de poderes, ou o confronto entre capital e trabalho que se manifesta por meio de revoltas e rebeliões. Nesse caso, ver: Tiriba e Magalhães (2018), Pérez Garcia (2017) e Nascimento (2019). B) Espaços/tempos da crise do capital e do trabalho assalariado, nos quais as estratégias associativas de trabalho se configuram como parte integrante da economia popular solidária, dos movimentos de fábricas ocupadas, do Movimento dos Trabalhadores Rurais Sem Terra, etc. Nesse caso, ver: Tiriba (2001). C) Espaços/tempos das práticas econômicas e culturais das comunidades e povos tradicionais: quilombolas, caiçaras, indígenas, pescadores, pantaneiros, artesãos, pequenos produtores rurais, etc. Nesse caso, ver: Tiriba e Fischer (2015); Tiriba e Santana (2017); Tiriba (2018); Alves e Tiriba (2018); Tiriba e Souza (2020); Souza (2020).

${ }^{6}$ Sem dúvida, essa obra-prima de Antônio Cândido nos dá algumas pistas para prosseguir em busca de um conceito de modo de vida fundado na concepção materialista da história e da cultura.

${ }^{7}$ Acerca da discussão de Thompson com Raymond Williams sobre o que é e o que não é cultura, bem como modos de vida como modos de conflito, ou modo de luta, ver o capítulo 3 de Mattos (2012).

${ }^{8}$ Entre outros, ver Tiriba e Fischer (2015); Tiriba e Santana (2017); Tiriba (2018); Alves e Tiriba (2018); Tiriba e Souza (2020); Souza (2020).

9 Tomando como exemplo as terras dos indígenas na América, Ellen Wood (2000, p. 22) analisa que, no capitalismo, "um proprietário (ou senhor da terra) empreendedor, disposto a realizar os 'melhoramentos' fundamenta seu direito à propriedade não pelo seu trabalho direto, mas pela exploração produtiva da sua terra pelo trabalho de outras pessoas".

${ }^{10}$ Considerar formas de trabalho associado e atividades do circuito da economia popular e da economia capitalista, além de aposentadoria e fontes de complementação de renda.

${ }^{11}$ Considerar trabalho, saúde, moradia, alimentação, educação, cultura, lazer, desejo de sair ou permanecer na comunidade, etc.
\end{abstract}

Recebido em: 21 de fevereiro de 2021

Aprovado em: 08 de março de 2021 